\title{
Correction to: Practical approach to diastolic dysfunction in light of the new guidelines and clinical applications in the operating room and in the intensive care
}

\author{
F. Sanfilippo ${ }^{1^{*}} \mathbb{0}$, S. Scolletta ${ }^{2}$ A. Morelli ${ }^{3}$ and A. Vieillard-Baron ${ }^{4}$
}

\section{Correction to: Ann. Intensive Care (2018) 8:100} https://doi.org/10.1186/s13613-018-0447-x In the original article [1], the authors noticed a typographical error in Figure 2. The top left box should have included "E/A $<0.8$ and $\mathrm{E}<50 \mathrm{~cm} / \mathrm{s}$ ". Please see below the corrected Fig. 2.

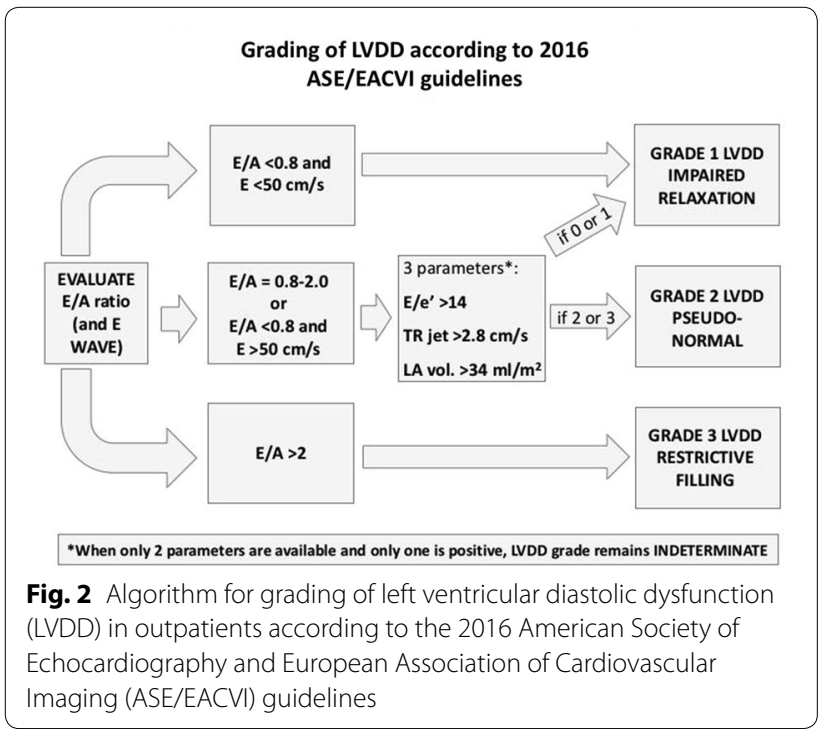

Author details

${ }^{1}$ Department of Anesthesia and Intensive Care, IRCCS-ISMETT (Istituto Mediterraneo per i Trapianti e Terapie ad alta specializzazione), Palermo, Italy. ${ }^{2}$ Unit of Intensive Care Medicine, Department of Medical Biotechnologies, University of Siena, Siena, Italy. ${ }^{3}$ Department of Anaesthesiology and Intensive Care, University of Rome, "La Sapienza", Rome, Italy. ${ }^{4}$ Hospital Ambroise Paré, Assistance Publique-Hôpitaux de Paris, Boulogne, France.

The original article can be found online at https://doi.org/10.1186/s1361 3-018-0447-x.

\section{Publisher's Note}

Springer Nature remains neutral with regard to jurisdictional claims in published maps and institutional affiliations.

Received: 30 October 2018 Accepted: 30 October 2018 Published online: 06 November 2018

\section{Reference}

1. Sanfilippo F, Scolletta S, Morelli A, Vieillard-Baron A. Practical approach to diastolic dysfunction in light of the new guidelines and clinical applications in the operating room and in the intensive care. Ann Intensive Care. 2018;8:100.

\footnotetext{
${ }^{*}$ Correspondence: filipposanfi@yahoo.it

${ }^{1}$ Department of Anesthesia and Intensive Care, IRCCS-ISMETT (Istituto Mediterraneo per i Trapianti e Terapie ad alta specializzazione), Palermo, Italy

Full list of author information is available at the end of the article
} 